Ciencia y Salud, Vol. V, No. 2, mayo-agosto, 2021 •ISSN (impreso): 2613-8816 • ISSN (en línea): 2613-8824

DOI: https://doi.org/10.22206/cysa.2021.v5i2.pp149-157

\title{
EXPERIENCIA ACUMULADA CON CASOS DE BEZOAR POR EL DEPARTAMENTO DE CIRUGÍA PEDIÁTRICA. HOSPITAL INFANTIL DOCTOR ROBERT REID CABRAL (HIRRC), REPÚBLICA DOMINICANA
}

\section{Experience accumulated with cases of Bezoar by the department of Pediatric Surgery. Robert Reid Cabral Children's Hospital, Dominican Republic}

\author{
Elvyn Alcántara ${ }^{a}$, Firelys Roa ${ }^{b}$, Juan Espinosac, Esfraylin Duarte ${ }^{\mathrm{d}}$ y Luis Féliz
}

Recibido: 3 de abril, $2020 \bullet$ Aprobado: 6 de julio, 2020

Cómo citar: Alcántara E, Roa F, Espinosa J, Duarte E, Feliz L. Experiencia acumulada con casos de bezoar por el departamento de Cirugía Pediátrica. Hospital Infantil Doctor Robert Reid Cabral (HIRRC), República Dominicana. cysa [Internet]. 10 de junio de 2021 [citado 16 de junio de 2021];5(2):149-57. Disponible en: https://revistas.intec.edu.do/index.php/cisa/article/view/2216

\section{Resumen}

La obstrucción intestinal puede ocurrir a cualquier edad, desde recién nacidos hasta adultos. La etiología de la obstrucción varía mucho, dependiendo de la edad y antecedentes quirúrgicos del paciente. Causas congénitas comunes que incluyen atresia, estenosis, malrotación, enfermedad de Hirschsprung, ano imperforado y meconio las enfermedades del recién nacido, pero también pueden ser otras las causas de obstrucción, como la ingestión de varios cuerpos extrańos, incluidos cacahuetes, fitobezoares, tricobezoares y pica en personas con discapacidad mental, falta de nutrientes en pacientes con déficit alimentario puede causar obstrucción intestinal parcial o completa en los nińos, así como trastornos del crecimiento debido a desnutrición. Las ubicaciones comunes de obstrucción intestinal causada por cuerpos extraños incluyen la salida

\footnotetext{
a Director Servicio de Cirugía Pediátrica. Cirujano Pediatra del Hospital Infantil Dr. Robert Reid Cabral (HIDRRC), Santo Domingo, República Dominicana. Correo-e: drelvynalcantarar@gmail.com

b Coordinadora Residencia de Cirugía Pediátrica. Cirujana Pediatra del Hospital Infantil Dr. Robert Reid Cabral (HIDRRC), Santo Domingo, República Dominicana. Correo-e: firelysroa@hotmail.com

c Cirujano Pediatra del Hospital Infantil Dr. Robert Reid Cabral (HIDRRC), Santo Domingo, República Dominicana. Correo-e: mannyespinosa@hotmail.com
}

\begin{abstract}
Bowel obstruction can occur at any age from newborn to adults. The etiology of the obstruction varies greatly, depending on the age and surgical history of the patient. Common congenital causes including atresia, stenosis, malrotation, Hirschsprung's disease, imperforate anus, and meconium diseases of the newborn, but ingestion of various foreign bodies, including peanuts, phytobezoars, trichobezoars, and pica in people can also be other causes of obstruction. mentally disabled, lack of nutrients in patients with food deficit, can cause partial or complete intestinal obstruction in children as well as growth disorders due to malnutrition. Common locations of intestinal obstruction caused by foreign bodies include gastric outlet; as evidenced in Rapunzel's syndrome, and the terminal ileum. Ingestion of multiple magnets carries its
\end{abstract}

\footnotetext{
d Jefe de Residente de Cirugía Pediátrica del Hospital Infantil Dr. Robert Reid Cabral (HIDRRC), Santo Domingo, República Dominicana. Correo-e: esfraylindc@gmail.com

e Residente de Cirugía Pediátrica del Hospital Infantil Dr. Robert Reid Cabral (HIDRRC), Santo Domingo, República Dominicana. Correo-e: drluisfeliz@hotmail.com
} 
gástrica; como se evidencia en el síndrome de Rapunzel, y el íleon terminal. La ingestión de múltiples imanes conlleva su propio conjunto de riesgos de obstrucción intestinal, vólvulo y fístulas intestinales y, por lo general, requiere exploración quirúrgica.

Palabras clave: abdomen agudo; Tricobezoar; Fitobezoar; dolor abdominal; bezoares; obstrucción de la salida gástrica; tricofagia; tricotilomanía.

\section{Introducción}

Un bezoar es la acumulación de sustancias orgánicas dentro del tracto gastrointestinal. El tricobezoar es una acumulación de cabello, generalmente, en las porciones proximales del tracto gastrointestinal, $y$ es una enfermedad rara. El término bezoar deriva de la palabra bazahr, que era usada por los árabes para describir antídotos de venenos extraídos de los animales, y trico deriva de la palabra griega trich, que significa 'cabello'. 1,2

La formación del tricobezoar comienza con la acumulación de cabello en los pliegues gástricos, el cual es altamente resistente a la digestión y a la perístasis, debido a su superficie lisa. La ingestión crónica lleva a su agrupación junto con otras sustancias presentes, como moco y alimento, y forma un cuerpo extraño que, generalmente, se limita al estómago $^{3}$, aunque se pueden encontrar con gran frecuencia en intestino delgado y ciego, donde a nivel del tracto ciego es un sitio muy poco común para los bezoares asociados con una sintomatología abdominal deficiente. ${ }^{3-5}$ En algunos casos, este puede extenderse hasta el intestino o el colon. Los materiales que componen los bezoares comprenden material vegetal (fitobezoar), que es el tipo más común de bezoares; restos de frutas (diospirobezoares), que es el subtipo de fitobezoar más común; cabello (tricobezoar) y medicamentos ingeridos (farmacobezoar). Las personas con riesgo de desarrollar esta patología son aquellas con alteraciones own set of risks for intestinal obstruction, volvulus, and intestinal fistulas, and generally requires surgical explore.

Keywords: acute abdomen; Trichobezoar; Phytobezoar; abdominal pain; bezoars; gastric outlet obstruction; trichophagia; trichotillomania.

anatómicas o en la motilidad gastrointestinal, como pacientes diabéticos, con patologías neurológicas, alteraciones en la secreción de jugo gástrico o con cirugías gástricas previas. Las enfermedades psiquiátricas y el retardo mental se asocian con los bezoares, debido a la pica y a la ingesta compulsiva y excesiva de comida. ${ }^{2}$ Los tricobezoares se presentan más en las mujeres, entre las adolescentes y las adultas jóvenes. Los bezoares gástricos se encuentran entre las etiologías del dolor abdominal crónico en la niñez que, cuando no se diagnostica, puede resultar en complicaciones graves, como ulceración gástrica, hemorragia y perforación, invaginación intestinal y obstrucción del intestino delgado. ${ }^{4}$

A continuación, se presenta la experiencia acumulada durante dos años en nuestro servicio de cirugía pediatría, en el Hospital Infantil Robert Reid Cabral.

\section{Objetivos}

Proporcionar y documentar la experiencia de nuestro departamento de cirugía pediátrica en los años 2018 hasta el 2020.

\section{Casos clínicos (Presentaciones de casos)}

Se presentará la experiencia de los pacientes de nuestro departamento desde su historia clínica hasta el desenlace quirúrgico 


\section{Paciente no.1}

Se trata de paciente masculino de 3 años de edad, el cual nos presentan al departamento de Cirugía con historia de dolor abdominal tipo cólico de $24 \mathrm{~h}$ de evolución acompañado de pérdida del apetito $\mathrm{y}$, posteriormente, vómitos de contenido gástrico en múltiples ocasiones, así como fiebre de 18 h de evolución no termometrada sin predominio de horario.

Paciente fue asistido en sub centros de salud, donde se prestó asistencia sintomática y fue egresado posteriormente. Ante persistencia del cuadro acuden nuevamente y le realizan sonografia que reporta hallazgos a favor de invaginación intestinal (figura 1) por lo que es presentado en cirugía.

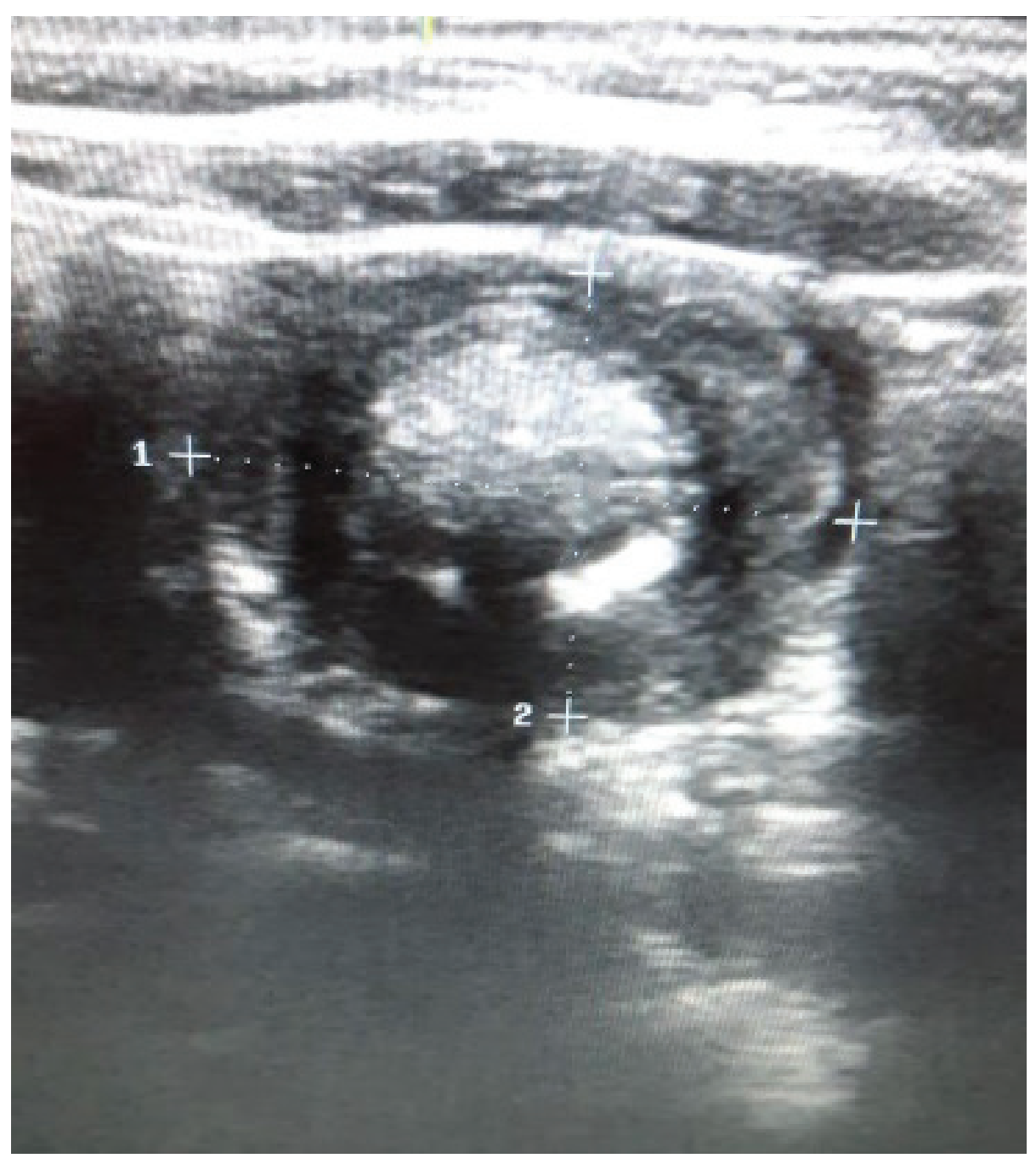

Figura 1. Imagen de sonografía: se evidencia signo de diana con paredes intestinales engrosadas con ausencia de luz. Nótese la escasa cantidad de líquido entre el asa invaginante e invaginada.

$\mathrm{Al}$ evaluar paciente se evidencia somnoliento, febril $\left(38^{\circ} \mathrm{C}\right)$, eupneico, deshidratado con mucosa oral seca, leve palidez de piel y mucosas con adecuado llenado capilar y temperatura de extremidades. Abdomen plano, simétrico, perístasis disminuida en tono y frecuencia, manejable, depresible, no doloroso, masa blanda y móvil en mesogastrio. Tacto rectal con esfínter eutónico, ampolla hipertérmica, no masas/irritación peritoneal, dedo examinador limpio a la salida. 
Tras los datos al examen físico y de imágenes se traslada a Quirófano donde se encuentran múltiples invaginaciones yeyunales de pocos centímetros. Se palpa cordón y "placas" intraluminales. Se ordeña hasta recto y se obtiene Tricobezoares (figura 2).
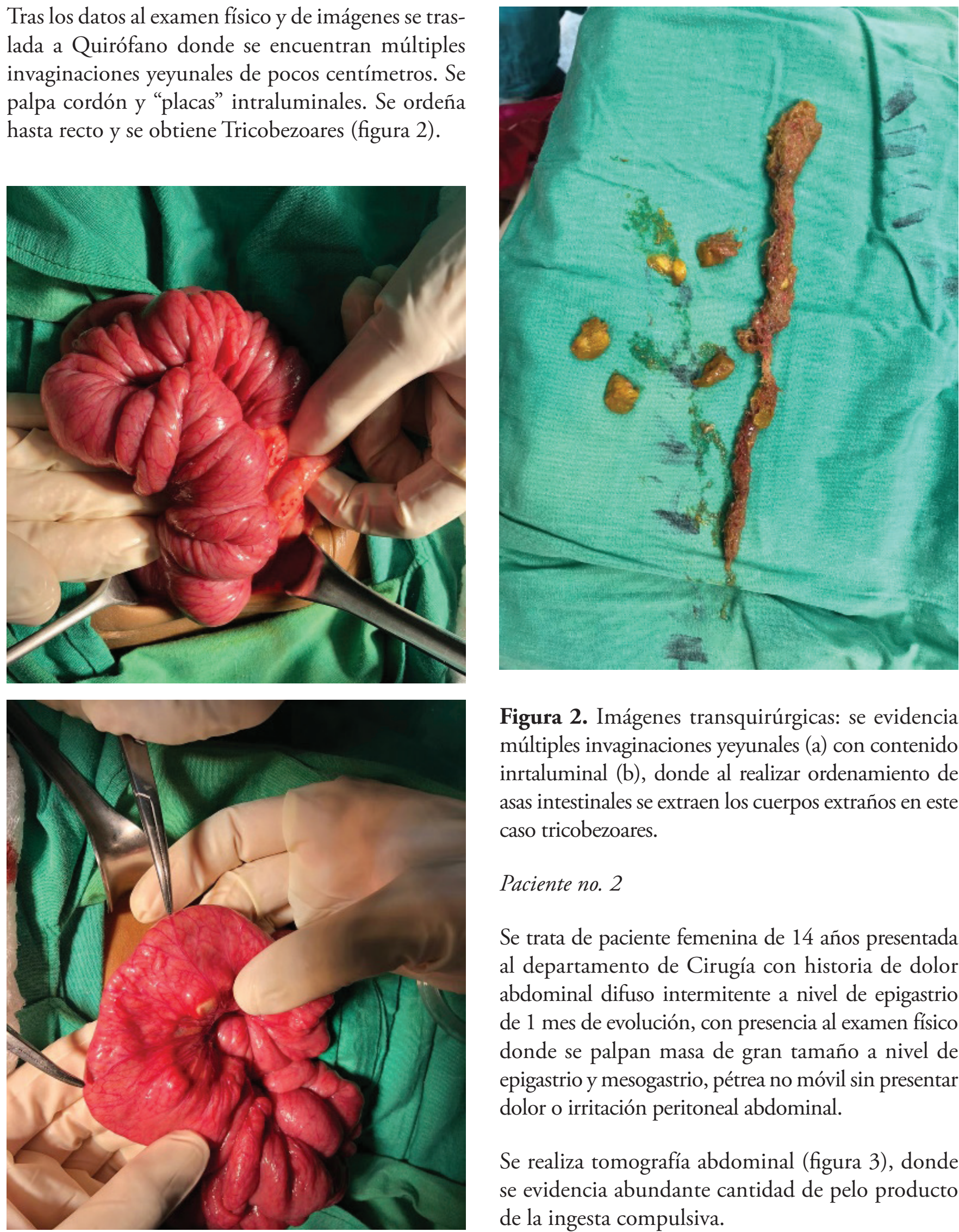

Figura 2. Imágenes transquirúrgicas: se evidencia múltiples invaginaciones yeyunales (a) con contenido inrtaluminal (b), donde al realizar ordenamiento de asas intestinales se extraen los cuerpos extraños en este caso tricobezoares.

\section{Paciente no. 2}

Se trata de paciente femenina de 14 años presentada al departamento de Cirugía con historia de dolor abdominal difuso intermitente a nivel de epigastrio de 1 mes de evolución, con presencia al examen físico donde se palpan masa de gran tamaño a nivel de epigastrio y mesogastrio, pétrea no móvil sin presentar dolor o irritación peritoneal abdominal.

Se realiza tomografía abdominal (figura 3), donde se evidencia abundante cantidad de pelo producto de la ingesta compulsiva. 

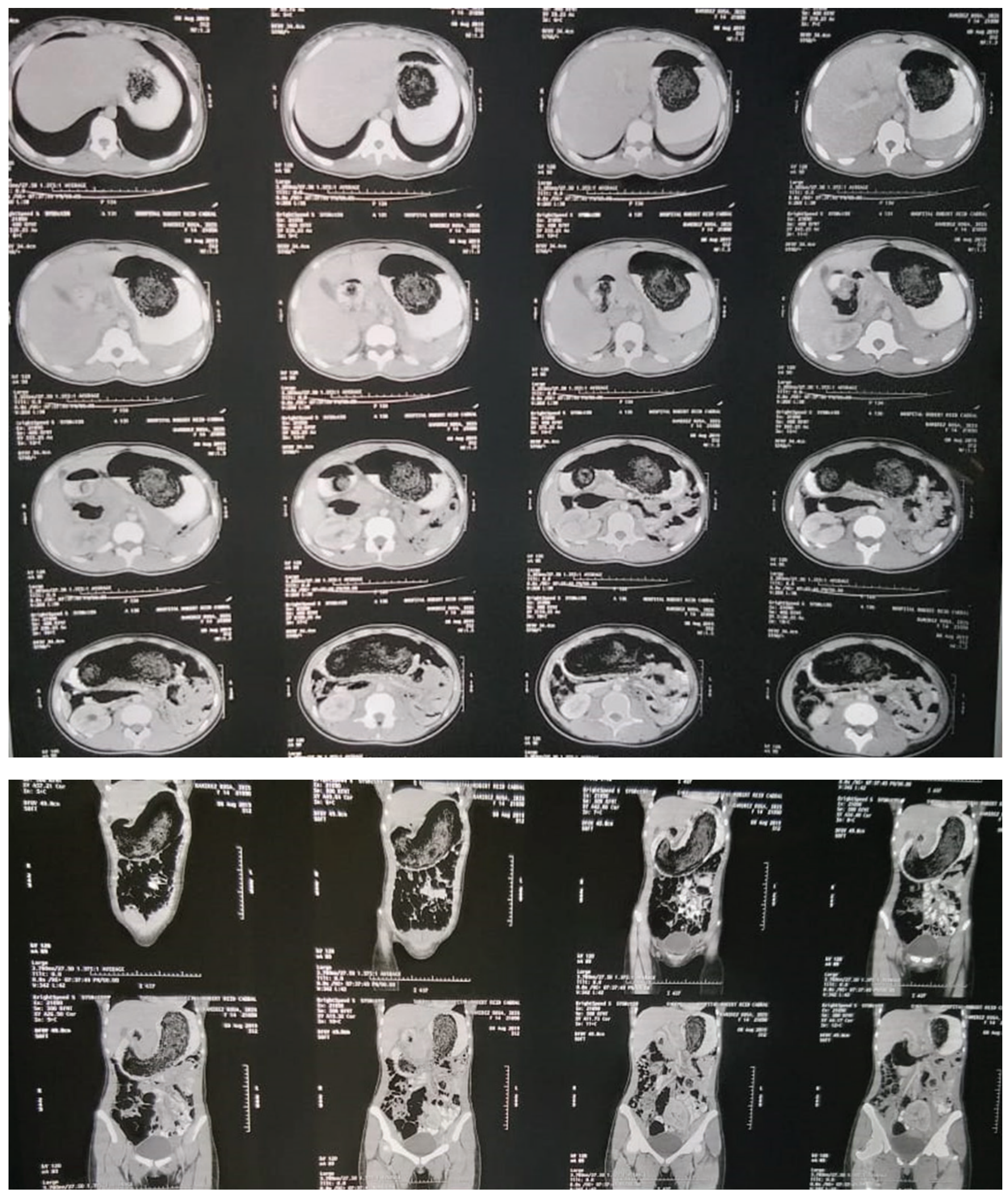

Figura 3. Tomografía abdominal en cortes sagital y coronales; se evidencia abundante cantidad de pelo sin presentar datos de obstrucción. 
Al examen físico: abdomen semigloboso, perístasis presente, masa palpable de gran tamaño de epigastrio a hipocondrio derecho e izquierdo pétrea no dolorosa a la palpación, sin datos obstructivos completos irritación peritoneal.

En quirófano se le realizó laparotomía + gastrostomía + extracción de cuerpo extraño + gastrorrafia.

\section{Paciente no. 3}

Se trata de paciente femenina de 11 años presentada al departamento de cirugía con historia de dolor abdominal difuso intermitente a nivel de epigastrio de evolución no especificada por los familiares, con presencia al examen físico de alopecia (figura 4), trastorno del crecimiento con desarrollo pondero estatural por desnutrición. Donde se palpan masa de gran tamaño a nivel de epigastrio y mesogastrio, pétrea no móvil sin presentar dolor o irritación peritoneal abdominal.

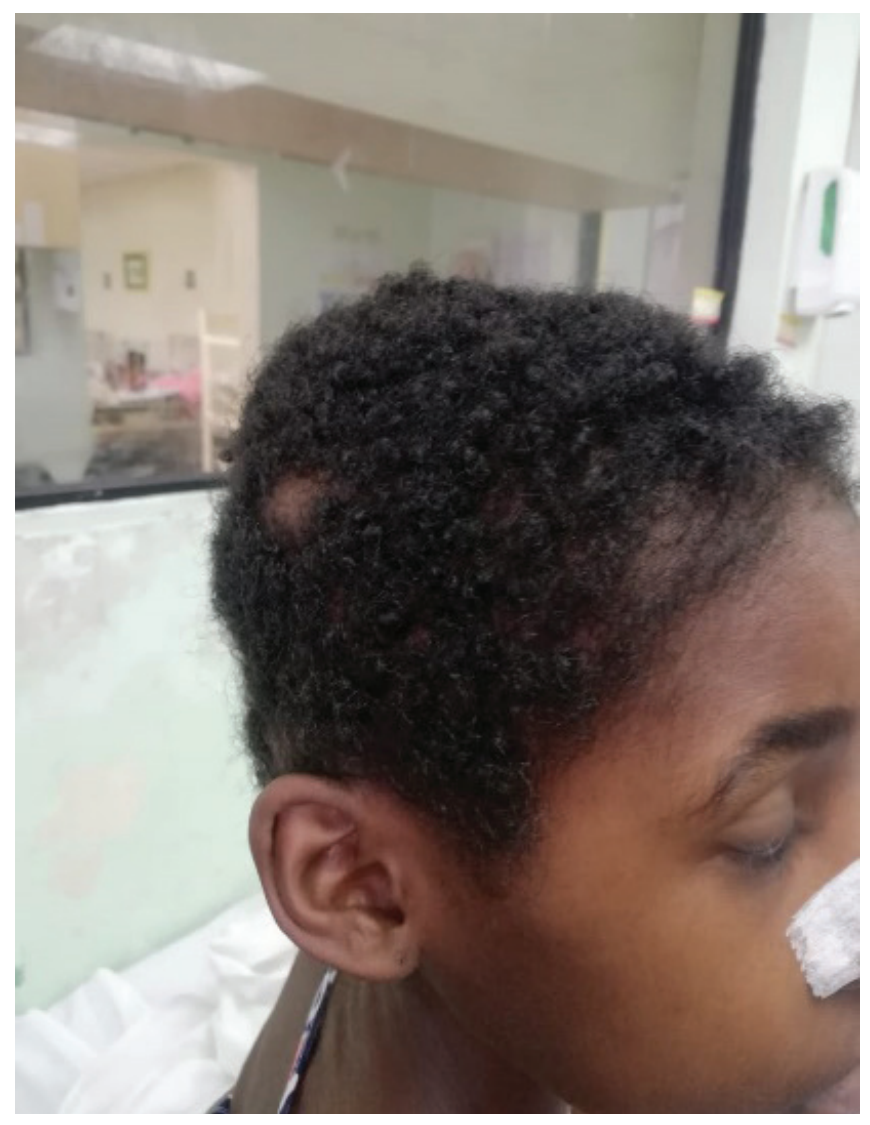

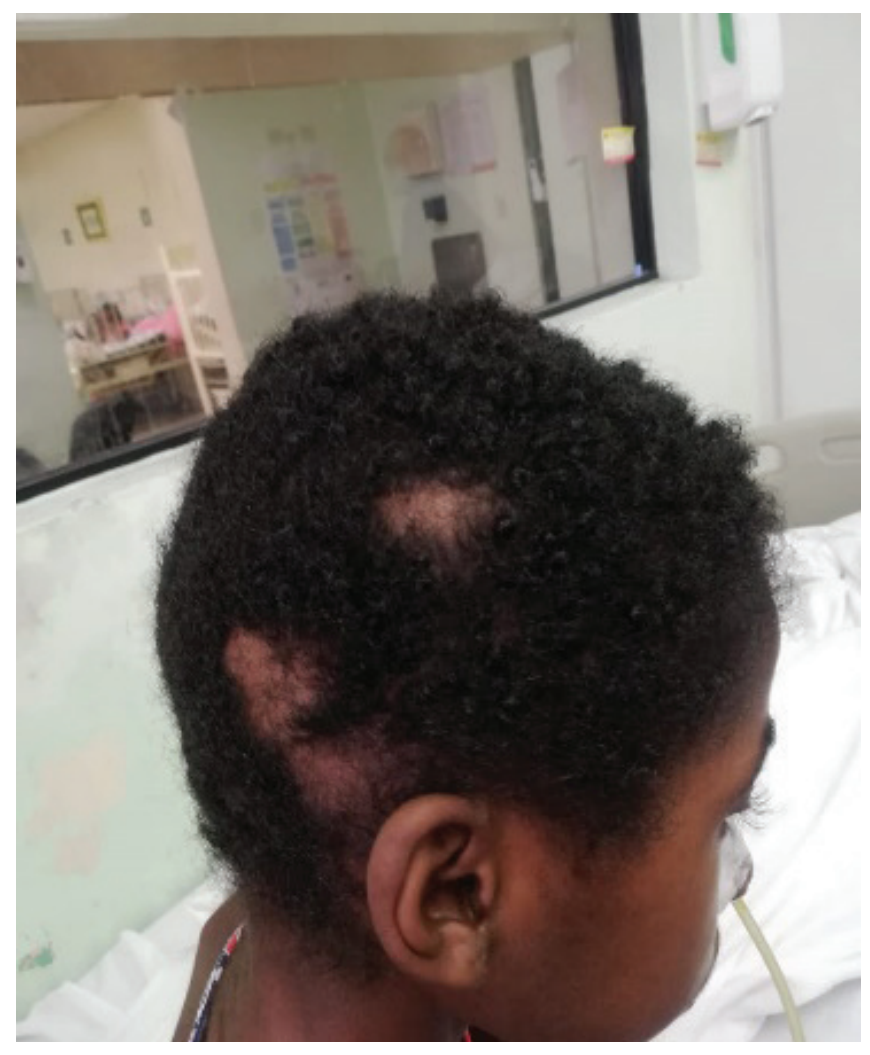

Figura 4. Imágenes de paciente: se evidencian múltiples áreas de alopecia anterior y posterior en cuero cabelludo.

Se realiza tomografía abdominal (figura 5), donde se evidencia abundante cantidad de pelo desde el estómago hasta el duodeno, producto de la ingesta compulsiva; sugerente de síndrome de Rapunzel.

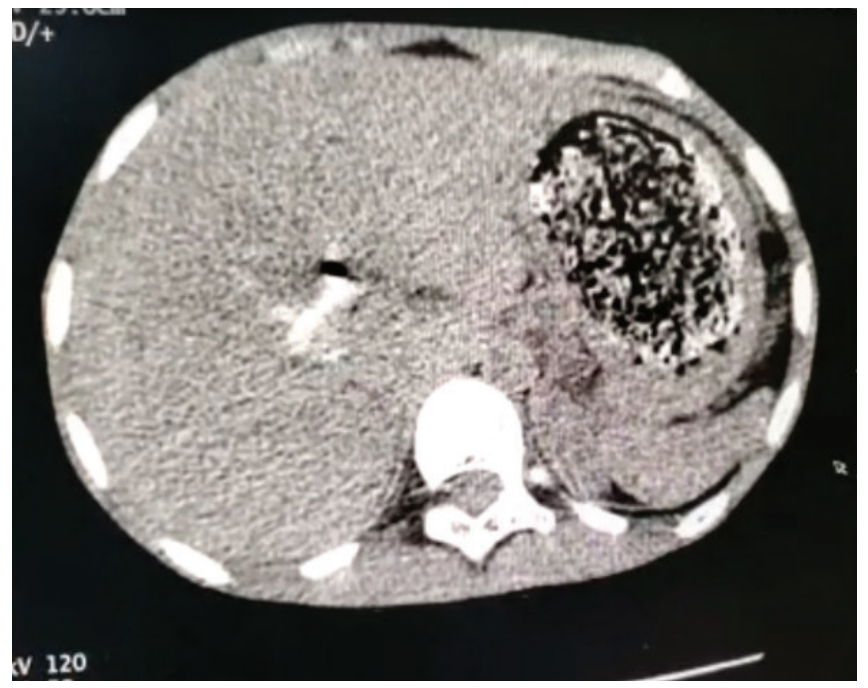



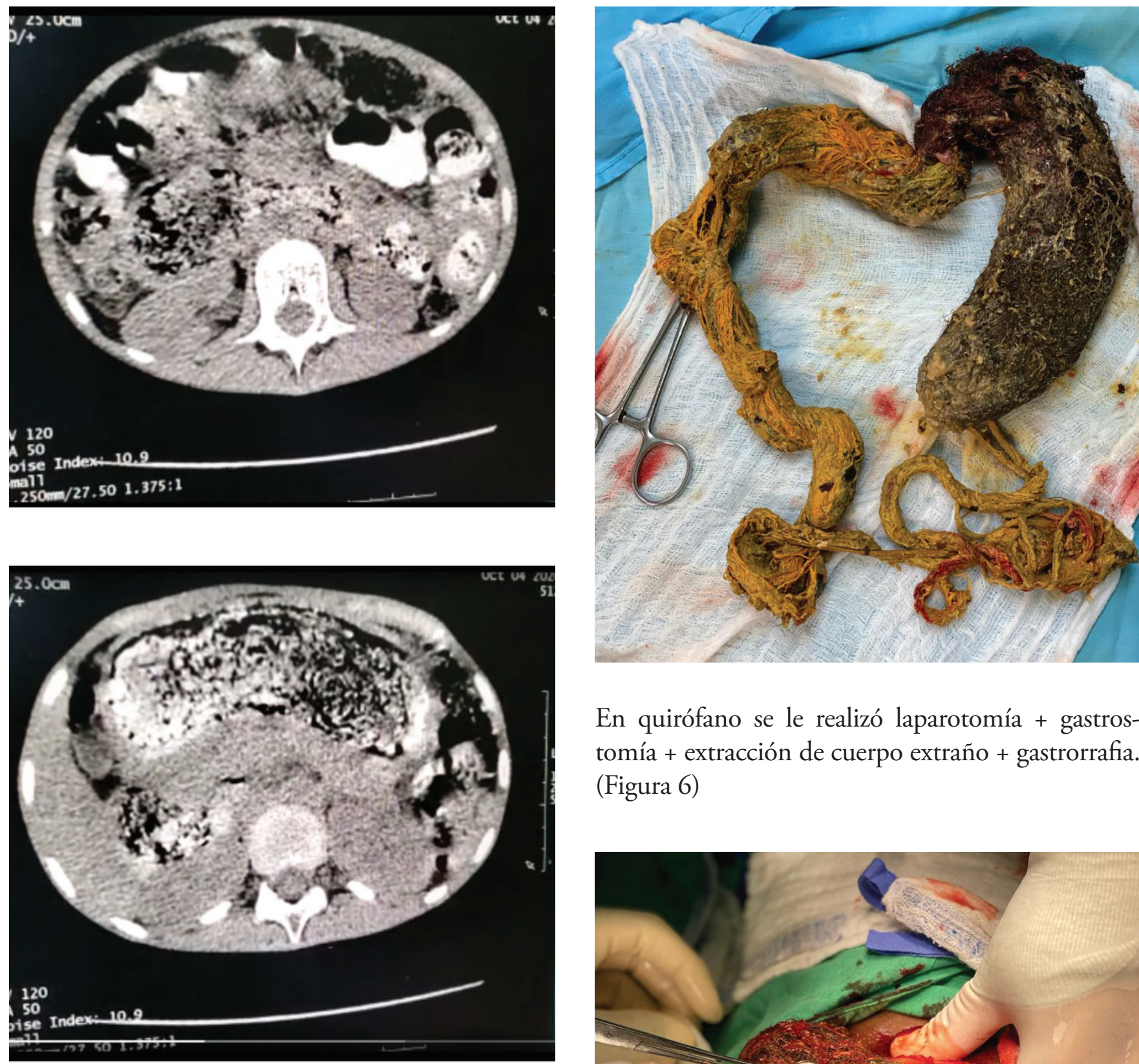

En quirófano se le realizó laparotomía + gastrostomía + extracción de cuerpo extraño + gastrorrafia. (Figura 6)

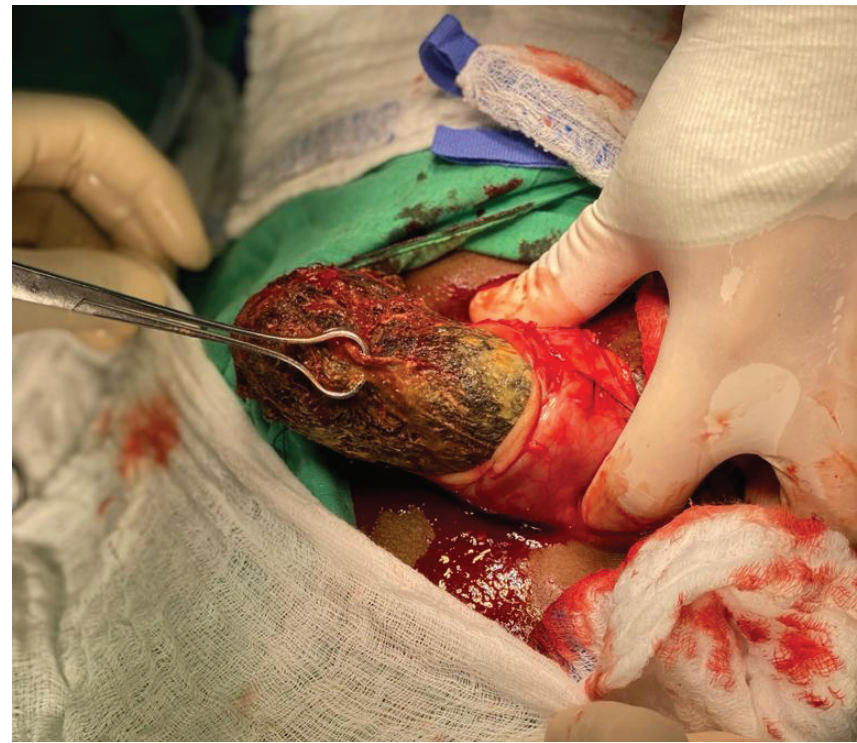

Al examen físico: abdomen semigloboso, perístasis presente, masa palpable de gran tamaño de epigastrio a hipocondrio derecho e izquierdo pétrea no dolorosa a la palpación, sin datos obstructivos completos irritación peritoneal.

Figura 6. Imágenes transquirúrgicas: se evidencia tricobezoar de gran tamaño desde estómago hasta $60 \mathrm{cms}$ de yeyuno donde se extrae por gastrostomía. 


\section{Discusión}

Los bezoares a nivel del tubo digestivo son entidades infrecuentes en las edades pediátricas. ${ }^{1,2}$ La mayoría de los casos corresponden a tricobezoares, el cual se relaciona con nuestra casuística, que son hallazgos de cabello encontrados en el estómago secundarios a la ingesta compulsiva, así como trastornos alimenticios. La incidencia también se expresa en nuestro trabajo donde se evidencia con mayor predominio al sexo femenino. ${ }^{1,2}$ Los bezoares se pueden encontrar en el estómago en menos del $0,5 \%$ de los individuos sometidos a endoscopías de las vías digestivas altas como hallazgo inusual. El espectro clínico de estos pacientes es variable y se evidencia en edades escolares la mayoría de ellos. Los síntomas, típicamente, comprenden zonas de alopecia, dolor abdominal, náuseas, vómitos, pérdida de peso, anorexia, saciedad temprana y síntomas relacionados con la anemia, como mareo, palpitaciones y cansancio. ${ }^{8}$ Similar a la encontrada en nuestro caso, dado que los pacientes presentaban, al momento de la inspección, áreas de alopecia que indicaron la tricotilomanía y la posible tricofagia, asociadas al dolor abdominal crónico, por el que había consultado previamente, pero sin un diagnóstico claro. Al momento de la realización del diagnóstico, se presentaban náuseas y pérdida de peso, aunque sin alteraciones relacionadas con síntomas anémicos. Las masas palpables en el abdomen también se encuentran dentro del espectro clínico. ${ }^{1,2,4}$

Este hallazgo fue fundamental en nuestro caso para realizar un correcto abordaje clínico y el posterior diagnóstico. Para el diagnóstico de esta entidad, se debe iniciar con un abordaje adecuado del paciente y una historia clínica completa. Dentro de los estudios imagenológicos están la ecografía y la tomografía computarizada de abdomen; sin embargo, el estándar de oro lo constituye la endoscopía de las vías digestivas altas, que desempeña un papel fundamental en su diagnóstico y tratamiento cuando es posible. El abordaje integral en estos pacientes es fundamental. Inicialmente, se intenta la extracción endoscópica, siempre y cuando sea factible. ${ }^{1,2,5}$

En aquellos casos en los que no lo es, el abordaje quirúrgico se convierte en el tratamiento de elección. En nuestra paciente, solo el caso 1 presentó hallazgo incidental en el procedimiento quirúrgico, por lo cual se recurrió a la gastrostomía tanto por el tamaño del tricobezoares, por las posibles complicaciones al intentar un abordaje laparoscópico. ${ }^{2,3,4}$

Existen estudios y meta análisis que nos ayudan a limitar el aspecto quirúrgico de los bezoares medicamentosos, farmacobezoar, por medio de Litotricia extracorpórea. Pero ante su desuso en la medicina actual no presenta mayores datos. Los enfoques no quirúrgicos, como la terapia dietética, la disolución enzimática y la eliminación endoscópica, se han considerado los pilares de la terapia. El propósito de este trabajo es determinar la eficacia de la litotricia electrohidráulica como una forma alternativa de tratamiento de los bezoares gástricos. ${ }^{6,7}$

\section{Conclusión}

El seguimiento interdisciplinario se convierte en una importante herramienta para explorar y tratar las causas psicoemocionales subyacentes, así como la psicoeducación hacia los pacientes y sus familiares sobre los riesgos que conlleva la recidiva del cuadro clínico. En este caso, al tratarse de una paciente que se encuentra en un ciclo vital temprano, el fortalecimiento y la adecuada estructuración de una personalidad sólida son preponderantes para evitar posteriores recurrencias.

Además del manejo quirúrgico, el abordaje por el equipo de Psiquiatría es fundamental para prevenir la recurrencia de estos casos, la cual alcanza cifras de hasta el $20 \%$ si no se controlan los factores de ansiedad. Por ello, es importante identificar las causas asociadas al trastorno, que, en nuestro caso, fueron el maltrato físico previamente recibido por los pacientes y escenas asociadas, las cuales causaban ansiedad. 


\section{Financiación}

No hemos recibido financiación para la realización del manuscrito.

\section{Conflicto de intereses}

Ninguno de los autores presenta conflicto de intereses.

\section{Bibliografía}

1. Coran AG. Pediatric Surgery. "Other Causes of Intestinal Obstruction”. By Wolfgang Stehr and Cynthia A. Gingalewski Cap 38. p. 517-524. 7th edition (C) Elsevier Saunders 2010.

2. Castrillón Peña EL, Espinosa Moreno MF, Barrios Torres JC, Forero Niño EE. Tricobezoar gastroduodenal en la edad escolar. Caso clínico. Arch Argent Pediatr. 2019;117(3):e284-7.

3. Cannalire G, Conti L, Celoni M, Grassi C, Cella A, Bensi G, et al. Síndrome de Rapunzel: una causa infrecuente de anemia ferropénica grave y dolor abdominal que acude al servicio de urgencias pediátricas. BMC Pediatr. 2018;18(1):125.

4. Lynch KA, Feola PG, Guenther E. Tricobezoar gástrico: una causa importante de dolor abdominal que se presenta en el servicio de urgencias pediátricas. Pediatr Emerg Care. 2003;19(5):343-7.
5. Marilina D, Gaetana C, Eugenio R, Massimo Z. Un bezoar no oclusivo del ciego en un niño de 7 años: detección ecográfica y manejo de imágenes multimodal. J Ultrasonido. 2016;19(3):223-6.

6. Benes J, Chmel J, Jodl J, Stuka C, Nevoral J. Tratamiento de un bezoar gástrico mediante litotricia extracorpórea por ondas de choque. Endoscopia. 1991;23(6):346-8.

7. Kuo JY, Mo LR, Tsai CC, Chou CY, Lin RC, Chang KK. Tratamiento no quirúrgico de bezoares gástricos mediante litotricia electrohidráulica. Endoscopia. 1999;31(5):386-8.

8. Mahir S, Salih AM, Ahmed OF, Kakamad FH, Salih RQ, Mohammed SH, et al. Giant phytobezoar; an unusual cause of gastric outlet obstruction: A case report with literature review. Int J Surg Case Rep. 2020;67:154-6.

9. Honda H, Ikeya T, Kashiwagi E, Okada S, Fukuda K. Successful emergency endoscopic treatment of gastric outlet obstruction due to gastric bezoar with gastric pneumatosis. Case Rep Gastroenterol. 2017;11(3):718-23.

10. Guner A, Kahraman I, Aktas A, Kece C, Reis E. Gastric outlet obstruction due to duodenal bezoar: A case report. Int J Surg Case Rep. 2012;3(11):523-5. 